\title{
Direito constitucional à saúde: a possibilidade de concessão de redução de jornada de trabalho ao servidor portador de gonartrose fundamentada na lei no 8.112/90
}

Constitutional health law: the possibility of granting a reduction of working hours to the server with gonarthrosis based on Law No. 8,112 / 90

Derecho constitucional a la salud: la posibilidad de concesión de reducción de jornada de trabajo al servidor portador de gonartrase fundamentada en la ley $n^{0}$ 8.112/90

Nayara França Alves ${ }^{1 *}$, Daniel Melo da Silva Júnior ${ }^{2}$, Marcos Vinícius Rodrigues Quintairos ${ }^{1}$, Eliane de Jesus Miranda Santana ${ }^{1}$, Jacklinne Matta Correa ${ }^{1}$, Letícia Maria dos Santos Grangeiro ${ }^{1}$, Tiago Pereira dos Santos ${ }^{3}$.

\section{RESUMO}

Objetivos: $O$ presente trabalho tem por objetivo compreender os principais sintomas e dificuldades enfrentadas por portadores de Gonartrose, para que deste modo seja possível apresentar os benefícios trazidos pela equiparação dessa doença como deficiência física a pretexto de permitir melhor tratamento médico após a redução da jornada de trabalho do servidor, permitida atualmente pela legislação apenas para deficiências físicas. Método: Exploratório, de abordagem qualitativa, método dialético e procedimentos bibliográfico e documental. Resultados: A equiparação da Gonartrose à deficiência física ao garantir o direito à redução da jornada de trabalho garante também a possibilidade de realização de várias das atividades necessárias para a diminuição dos impactos negativos trazidos pela doença como fisioterapia, hidroginástica e acupuntura, diminuindo os problemas com a locomoção, o próprio desempenho das atividades laborativas e atividades consideradas normais, como andar, sentar, abaixar-se, dirigir ou subir escadas. Deste modo, essa benesse garante a possibilidade de tratamento, que associado a mudanças de estilo de vida, em um processo de cuidado contínuo, que nem sempre leva à cura, pode caracterizar significativa melhora na qualidade de vida do servidor. Conclusões: A Gonartrose deve ser equiparada a deficiência física para fins de redução de jornada de trabalho para que o servidor possa utilizar o tempo disponível para realizar o tratamento necessário para diminuição dos sintomas.

Palavras-chave: Gornartrose; Saúde do Servidor Público; Deficiência; Redução de Jornada de Trabalho.

\footnotetext{
ABSTRACT

${ }^{1}$ Instituto Federal do Amapá, Macapá-AP. *E-mail: nayara.alves@ifap.edu.br

${ }^{2}$ Advogado, Macapá-AP.

${ }^{3}$ Bacharel em Direito, CEAP, Macapá-AP.
}

Objectives: This study aims to understand the main symptoms and difficulties faced by patients with Gonartrose, so that it is possible to present the benefits brought about by the equation of this disease as a physical disability under the pretext of allowing better medical treatment after the reduction of the server work, currently permitted by legislation only for physical disabilities. Method: Exploratory, qualitative approach, dialectical method and bibliographic and documentary procedures. Results: Gonartrose's physical disability by guaranteeing the right to reduce working hours also guarantees the possibility of performing several 
activities necessary to reduce the negative impacts caused by the disease, such as physiotherapy, water aerobics and acupuncture, reducing problems with locomotion, the performance of work activities and activities considered normal, such as walking, sitting, stooping, driving or climbing stairs. Thus, this benefit guarantees the possibility of treatment, which associated with changes in lifestyle, in a process of continuous care, which does not always lead to cure, can characterize significant improvement in the quality of life of the server. Conclusions: Gonartrose should be considered as physical impairment for the purpose of reducing working hours so that the server can use the time available to perform the necessary treatment to reduce the symptoms.

Key words: Gornartrose; Public Server Health; Deficiency; Reduction of working hours.

\section{RESUMEN}

Objetivos: El presente trabajo tiene por objetivo comprender los principales síntomas y dificultades enfrentadas por portadores de Gonartrosis, para que de este modo sea posible presentar los beneficios aportados por la equiparación de esa enfermedad como deficiencia física con el pretexto de permitir un mejor tratamiento médico después de la reducción de la jornada de trabajo trabajo del servidor, permitida actualmente por la legislación sólo para discapacidades físicas. Método: Exploratorio, de abordaje cualitativo, método dialéctico y procedimientos bibliográfico y documental. Resultados: La equiparación de la Gonartrosis a la deficiencia física al garantizar el derecho a la reducción de la jornada de trabajo garantiza también la posibilidad de realizar varias de las actividades necesarias para la disminución de los impactos negativos traídos por la enfermedad como fisioterapia, hidroginástica y acupuntura, disminuyendo los problemas con la locomoción, el propio desempeño de las actividades laborativas y actividades consideradas normales, como caminar, sentarse, bajar, dirigir o subir escaleras. De este modo, esta benéfica garantiza la posibilidad de tratamiento, que asociado a cambios de estilo de vida, en un proceso de cuidado continuo, que no siempre lleva a la cura, puede caracterizar significativa mejora en la calidad de vida del servidor. Conclusiones: La Gonartrosis debe ser equiparada a la deficiencia física para fines de reducción de jornada de trabajo para que el servidor pueda utilizar el tiempo disponible para realizar el tratamiento necesario para la disminución de los síntomas.

Palabras clave: Gornartrosis; Salud del Servidor Público; discapacidad; Reducción de Jornada de Trabajo.

\section{INTRODUÇÃO}

No âmbito do serviço público federal, o artigo 98, parágrafo 2º , da Lei 8.112/90 estabelece a possibilidade de flexibilização de horário de trabalho para servidores portadores de deficiência (sic), desde que comprovada a necessidade por junta médica oficial (BRASIL,1990). Trata-se, portanto, de importante instrumento de valorização da dignidade da pessoa humana, em respeito às peculiaridades enfrentadas pelos servidores com deficiência, em especial aqueles que necessitam realizar tratamentos que não se compatibilizam com a jornada da repartição em que laboram, tendo direito, assim, a uma redução da jornada semanal.

Ocorre que a parca literatura acerca da possibilidade de diversas outras doenças não tidas como deficiência, mas que demandam tratamento contínuo, sejam passíveis de concessão do direito ao horário especial para seus portadores acaba por causar desinformação perante aqueles que poderiam ser beneficiados pela redução de jornada, e assim conseguir uma melhor qualidade de vida.

Nesse contexto, pode-se englobar a Gonartrose como uma doença crônica que está relacionada a causas múltiplas e caracterizadas por início gradual, desta forma, ainda encontram-se percalços pela dificuldade de diagnóstico correto da doença, que pode se incerto por médicos especializados por curto, médio ou longo prazo. Assim, o tratamento é duradouro e pode sofrer alterações ao longo do curso clínico, por ocorrer a possibilidade de agudização dos períodos, e ainda podendo gerar incapacidades ao portador. Deste modo, utilizando-se das tecnologias leves, leve-duras e duras, acompanhados de mudanças de estilo de vida, esta doença necessita de cuidado contínuo, e que infelizmente, nem sempre levará o portador à cura (MINISTÉRIO DA SAÚDE, 2013, p. 5). 
Deste modo, tendo em vista que a Gonartrose também chamada de osteoartrose apresenta características de uma doença crônica, assim buscaremos analisar a possibilidade jurídica da doença de Código Internacional de Doenças- CID 10 - M17.9 Gonartrose, poder ser equiparada à deficiência física para efeitos da concessão de horário especial de servidor público federal, vez que não se encontra no rol de deficiências que permitem essa benesse.

Desse modo, desvendar a possibilidade de enquadrar, mesmo que de forma análoga, a Gonartrose como deficiência física para efeitos de redução de jornada de trabalho apresenta grande relevância, a considerar o número de servidores que possuem essa doença passíveis de serem beneficiados, bem como as peculiaridades enfrentadas pelos portadores dessa enfermidade, seja para locomoção, seja para o próprio desempenho das atividades laborativas, e atividades consideradas normais, como andar, sentar, abaixar-se, dirigir ou subir escadas.

Nesse sentido, as principais queixas dos portadores de Gonartrose são a dor e rigidez articular de curta duração, que em geral são localizadas no sítio anatômico envolvido, deste modo, nos joelhos a dor se faz presente em vários componentes das articulações, e assim, o uso de tratamentos fisioterapêuticos de mobilização ativa e passiva são os mais indicados VON MUHLEN (2000).

Por outro lado, por não haver decisões judiciais suficientes ou literatura médica que defina a Gonartrose como deficiência, o estudo das principais características da doença e suas consequências na vida de seus portadores se apresenta de grande relevância, pois pode dar ensejo à bases teóricas responsáveis por garantir esse direito a quem possui a doença e necessita realizar tratamento contínuo, o que hoje não é viabilizado muitas vezes pela incompatibilidade entre o horário das atividades laborais e os horários de tratamento, uma vez que de acordo com Von Muhlen (2000) a Gonartrose também chamada de Osteoartrose, osteoartrite na literatura anglo-saxã é a doença articular que apresenta maior grau de acometimento dos joelhos, essa doença ainda pode ser vista como uma forma de reumatismo pois envolve uma progressiva perda da cartilagem articular.

É preciso enfrentar a questão sob a perspectiva de saúde e qualidade de vida das pessoas portadoras de Gonartrose, bem como analisar os reflexos positivos que podem ser alcançados com a equiparação da enfermidade como deficiência, a considerar suas características limitadoras, e assim usufruir das benesses que podem minimizar os sofrimentos por quais passam os portadores da doença, bem como refletir sobre tal possibilidade em nosso ordenamento jurídico.

\section{MÉTODOS}

Trata-se de uma pesquisa com finalidade aplicada, com objetivo exploratório, de abordagem qualitativa, método dialético e procedimentos bibliográfico e documental.

Buscou-se analisar as características apresentadas pela Gonartrose em relação à literatura médica e ao Código Internacional de Doenças, bem como descrever os principais sintomas e suas consequências no diaa-dia das pessoas portadoras dessa enfermidade.

Verificou-se os processos arquivados em instituição federal de ensino, cuja jornada de trabalho regular é de 40 horas semanais, situada no município de Macapá, Amapá, localizado na região Norte do Brasil, com indeferimento dos pedidos de redução de jornada de trabalho de portadores de Gonartrose por não entender a instituição a existência de sustentáculo legal autorizador de concessão das reduções requeridas.

Buscou-se, então: a) conceituar pessoa com deficiência; b)descrever brevemente o conceito de Gonartrose; c) compreender os principais sintomas e dificuldades enfrentadas por portadores da doença; d) apresentar os benefícios trazidos pela equiparação da Gonartrose como deficiência para fins de tratamento médico decorrente da redução da jornada do servidor e, e) analisar a possibilidade jurídica de redução da jornada do servidor acometido por Gonartrose à luz do ordenamento jurídico, no item discussões.

Assim, o conceito de Gonartrose fora retirado de um blog na internet voltado para Ortopedia e 
Traumatologia, em que foi possível verificar ainda na rede mundial de computadores a escassez de literaturas sobre a temática, entretanto, nesse baixo acervo literário foi possível elencar os principais sintomas enfrentados por portadores de Gonartrose, bem como as dificuldades enfrentadas no dia-a- dia dessas pessoas. Verificou-se os tratamentos mais utilizados no enfrentamento da doença e seus impactos positivos na qualidade de vida das pessoas que os realizam.

Já a análise jurídica do conceito de pessoa com deficiência segundo a Convenção Internacional dos Direitos da Pessoa com Deficiência, do direito à saúde tutelado pela Constituição Federal e a análise da Lei $8.112 / 90$ são fundamentais para chegarmos às conclusões a respeito da possibilidade de se conceder o horário especial ao servidor. Ainda no item destinado às Discussões, analisamos a possibilidade jurídica à luz do ordenamento jurídico, em especial o princípio constitucional da dignidade da pessoa humana e da razoabilidade.

Procurou-se fundamentar, ainda, as conclusões em decisões judiciais que embora não digam respeito ao tema em específico, podem ser analisadas a fim de, analogicamente, justificar a finalidade da redução de jornada aqui defendida.

\section{RESULTADOS E DISCUSSÃO}

O conceito de pessoa com deficiência encontra-se atualmente definido no artigo $1^{\circ}$ da Convenção Internacional dos Direitos da Pessoa com Deficiência representada pelo Decreto 6.949/2009, que assim dispõe:

[...] "O propósito da presente Convenção é promover, proteger e assegurar o exercício pleno e equitativo de todos os direitos humanos e liberdades fundamentais por todas as pessoas com deficiência e promover o respeito pela sua dignidade inerente. Pessoas com deficiência são aquelas que têm impedimentos de longo prazo de natureza física, mental, intelectual ou sensorial, os quais, em interação com diversas barreiras, podem obstruir sua participação plena e efetiva na sociedade em igualdade de condições com as demais pessoas". (BRASIL, 2009).

Assim, o conceito de pessoa com deficiência encontra-se regulamentado pelo artigo $1^{\circ}$ da Convenção Internacional dos Direitos da Pessoa com Deficiência, que classifica deficiência em 4 tipos.

Por sua vez, Gonartrose encontra-se codificada no CID 10 - M17.9, o termo Gonartrose refere-se a "um tipo de artrose no joelho, causada por trauma, infecção, meniscectomia, lesão ligamentar ou qualquer outra forma de agressão ligamentar, podendo também surgir sem causa aparente" (SILVA, 2009).

Assim, de acordo com Silva (2009) temos que as principais características dessa doença, é o acometimento com maior frequência do sexo feminino comparado ao masculino, devido provavelmente das diferenças anatômicas existentes entre ambos os sexos, desta forma, o peso corporal que age diretamente sobre as articulações dos membros inferiores, logo os joelhos, apresentam em sua estrutura mecânica deformidades, que ocasionam estresses articulares, e caso não ocorra o tratamento correto, além das dores, espasmos musculares e limitação de movimento, esse descuido pode acarretar na ruptura da cartilagem, e com isso inviabilizar ou limitar ainda mais a locomoção do indivíduo. .

O tratamento inicial é clínico, com o objetivo é minimizar a dor, por meio de terapia não medicamentosa e medicamentosa. Assim, a primeira etapa seria que o portador da doença pudesse realizar em seu dia a dia mudanças de hábitos, como perda de peso e atividades físicas e uso de analgésicos, quando necessário. Posteriormente seria introduzido o uso de anti-inflamatórios não hormonais, em que são indicados o uso de medicação conrotetora e uma terapia física mais intensa. $O$ uso de corticoideterapia sistêmica estará indicada nos casos de doenças reumáticas e do colágeno. A seguir, o quadro clínico de maior intensidade, adicionamos ao tratamento anterior, o uso de medicação intra-articular, como infiltração de corticosteroide e a infiltração de ácido hialurônico intra-articular. Outra indicação para a infiltração do ácido hialurônico é em pacientes que não possuem condições para serem submetidos a intervenção cirúrgica como uma artroplastia (ÁVILA e de SÁ, 2011, p.122). 
Corroborando, Hinterholz e von Muhlen (2003) enfatizam sobre as possibilidades de tratamento que vai desde a seleção de um programa terapêutico que deve ser absolutamente individualizado, pois cada indivíduo possui uma estrutura anatômica, até ao uso de terapias físicas e ocupacionais, exercícios aeróbicos, entre outros, evidenciando a necessidade da educação do paciente e acima de tudo a perda de peso.

Diante disso, a equiparação da Gonartrose à deficiência física garante a possibilidade de realização de várias das atividades necessárias para a diminuição dos impactos negativos trazidos pela doença.

É de se notar que o conceito de pessoa com deficiência segundo Brasil (2015) é um conceito aberto, pois abarca as pessoas que têm impedimentos de longo prazo de natureza física, mental, intelectual ou sensorial, os quais, em interação com diversas barreiras, podem obstruir sua participação plena e efetiva na sociedade em igualdade de condições com as demais pessoas.

Não há uma relação de doenças ou características que venham a definir com segurança quem são aquelas pessoas que são enquadradas como deficientes, sendo que para a Administração Pública a Gonartrose não se equipara à deficiência física, uma vez que Brandão Neto (2016) corroborando com os pensamentos de Hinterholz e von Muhlen (2003) afirma que o tratamento da Gonartrose ainda pode ser feito por meio de medidas fisioterápicas, uso de órteses, palmilhas específicas, entre outras medidas, e ainda por tratamento farmacológico tendo como principal objetivo o alívio da dor, como por exemplo o uso de antiinflamatórios, analgésicos sistêmicos, analgésicos tópicos, infiltrações, entre outras modalidades terapêuticas.

De toda forma, o propósito inicial da concessão de horário especial para servidor com deficiência é garantir que se possa realizar tratamentos ou que se tenha o repouso necessário e adequado e condizentes com as limitações impostas pela deficiência.

A junta Médica Oficial composta segundo o Ministério do Planejamento, Orçamento e Gestão apresentase "por grupo de três médicos ou de três cirurgiões-dentistas" cujo objetivo é conceder o benefício, e ainda analisar as vantagens e as necessidades existentes em cada caso específico, prestigiando sempre o bem estar do servidor, sendo irrelevante o interesse da Administração no caso (MINISTÉRIO DO PLANEJAMENTO, ORÇAMENTO E GESTÃO, 2014).

Neste caso, se o servidor portador de Gonartrose sentir alguma melhora pelo fato da diminuição da jornada isso por si só resultará na melhora de qualidade de vida do servidor, assim passamos a pensar que se a diminuição da jornada permite que tratamentos como fisioterapia, hidroginástica, acupuntura tendo em vista que Harres (2008, p. 105) afirma que entre as opções terapêuticas conservadoras na gonartrose "aparece a Medicina Física que inclui a fisiatria, fisioterapia, as atividades físicas e a acupuntura, uma vez que esta busca evidenciar o seu importante papel coadjuvante no tratamento da gonartrose".

De qualquer modo, ainda que não se entenda ser possível o enquadramento da Gonartrose como deficiência física, é elementar que as características da doença demandam as mesmas atenções como outras deficiências, a exemplo da necessidade de fisioterapia.

Também é possível perceber que por ser uma doença degenerativa, a cura ainda parece distante da realidade, sendo os tratamentos os melhores meios de se garantir uma vida digna ao portador da doença e se evitar o avanço da degeneração. Assim Brandão Neto (2016) verbaliza sobre a possibilidade do tratamento cirúrgico como sendo uma "opção em pacientes com prejuízo da vida diária e falha do tratamento conservador. A indicação é realizada pelo ortopedista e devem ser considerados fatores como idade do paciente, a colocação de prótese em joelho pode ter benefício substancial na qualidade de vida".

Alguns Tribunais, porém, têm dado a interpretação de deficiência para a Gonartrose, conforme se extrai do seguinte julgado:

Apelação cível. Ação de obrigação de fazer. Passe livre no transporte coletivo urbano. Benefício concedido. Apelada portadora de artrose primária generalizada e radiculopatia. Carência financeira comprovada. Inteligência dos artigos 247 da lei orgânica do município do salvador c/c com o art. 5o do decreto federal $n^{\circ}$ 5.296/2004. Presença dos requisitos necessários concessão 
do benefício. Irresignação imotivada. Sentenca mantida em reexame necessário, concessão do passe livre no transporte coletivo urbano para a apelada. Recurso improvido. (classe: apelação, número do processo: 0160338-18.2009.8.05.0001, relator (a): gardenia pereira duarte, quarta câmara cível, Publicado em: 09/11/2016 )(TJ-BA - APL: 01603381820098050001, Relator: Gardenia Pereira Duarte, Quarta Câmara Cível, Data de Publicação: 09/11/2016).

É de se asseverar que 0 art. 5ำ do Decreto Federal ํo 5.296/2004 é a antiga legislação que definia o conceito de deficiência, comparando, assim, a Gonartrose como deficiência física.

Dessa feita, a redução da jornada de trabalho de servidor para que este se submeta aos tratamentos necessários para uma melhor qualidade de vida nada mais é do que o prestígio ao direito constitucional à saúde, insculpido na Constituição Federal de 1988.

A esse despeito, assim dispõe o art. 196 da Constituição Federal:

[...] Art. 196. A saúde é direito de todos e dever do Estado, garantido mediante políticas sociais e econômicas que visem à redução do risco de doença e de outros agravos e ao acesso universal e igualitário às ações e serviços para sua promoção, proteção e recuperação (BRASIL, 1988).

Note-se que a concessão da redução da jornada para efeitos de tratamento encontra-se em perfeita sintonia com o texto constitucional, a saúde sendo direito universal e o dever estatal de sua promoção, com políticas de reduções de agravos e ações que visem sua recuperação.

Estamos, portanto, diante de dispositivo que encontra-se acima da Lei 8.112/90, portanto possui eficácia imediata. A redução do termo pessoa com deficiência para fins de restringir a aplicabilidade do direito a redução de jornada causa uma injusta desigualdade, posto que servidores que demandam tratamento médico contínuo acabam por receber da Administração tratamentos jurídicos distintos.

Nesse sentido, Benjamin (1997) explica que nem sempre o termo "deficiente" possui significado idêntico para Medicina e para o Direito, pois "este está mais preocupado com as conotações sociais e culturais do problema do que com suas manifestações patológicas. Assim, em alguns casos, o sujeito, ainda que considerado 'normal' pela medicina, pode ser merecedor da tutela legal, vez que 'visto' como deficiente pelo grupo social".

Deve-se, portanto, aplicar a Constituição Federal para se garantir a finalidade da Lei 8.112/90, ao estabelecer o horário especial para portador de deficiência, como meio de promoção de política de saúde, posto que a finalidade da redução, já exaustivamente discutida no presente trabalho, é dar subsídios para uma melhor qualidade de vida para o servidor, seja ele deficiente, seja ele um doente crônico, como no caso da Gonartrose.

Por sua vez, a Constituição também garante a todo cidadão o direito à dignidade inerente à condição de pessoa humana, e nesse sentido, impedir que um portador de Gonartrose realize seus tratamentos em nome de um interesse da Administração significaria repelir a dignidade que cada ser humano carrega, e garantir a dignidade é garantir da melhor maneira possível a qualidade de vida das pessoas, sem descriminações desarrazoadas.

\section{CONCLUSÃO}

Assim, embora a enfermidade Gonartrose não seja considerada uma deficiência em si, suas consequências sintomáticas dão ensejo a uma considerável perda da qualidade de vida, demandando tratamento específico. Por esta razão, a doença deve ser equiparada a deficiência física para fins de redução de jornada de trabalho para que o servidor possa utilizar o tempo disponível para realizar o tratamento necessário para diminuição dos sintomas. Trata-se de procedimento que deve se sustentar no direito à saúde e na própria dignidade da pessoa humana, normas de direito responsáveis por justificar a legalidade da concessão. 


\section{REFERÊNCIAS}

1. ÁVILA SS, Sá MVC. Breve Revisão visão ortopédica do tratamento da gonartrose nas fases iniciais. Revista Brasileira de Medicina $\quad$ [serial line] $2011 . \quad$ Disponível em: <http://www.moreirajr.com.br/revistas.asp?fase=r003\&id_materia=4605>. Acesso em 30 jun 2018.

2. BRASIL. Constituição (1988).Constituição da República Federativa do Brasil. Brasília, DF: Senado Federal: Centro Gráfico, 1988.

3. BRASIL. Decreto № 6.949 , de 25 de agosto de 2009. Promulga a Convenção Internacional sobre os Direitos das Pessoas com Deficiência e seu Protocolo Facultativo, assinados em Nova York, em 30 de março de 2007. Disponível em: < http://www.planalto.gov.br/ccivil 03/ ato2007-2010/2009/decreto/d6949.htm>. Acesso em: 06 de fev. 2018.

4. BRASIL. Lei № 8.112, de 11 de dezembro de 1990. Dispõe sobre o regime jurídico dos servidores públicos civis da União, das autarquias e das fundações públicas federais. Disponível em: <http://www.planalto.gov.br/ccivil 03/Leis/L8112cons.htm>. Acesso em: 06 fev 2018.

5. BRASIL. Lei № 13.146, de 6 de julho de 2015. Institui a Lei Brasileira de Inclusão da Pessoa com Deficiência (Estatuto da Pessoa com Deficiência).Disponível em:< http://www.planalto.gov.br/Ccivil 03/ Ato20152018/2015/Lei/L13146.htm>. Acesso em: 24 jun 2018.

6. BENJAMIN AHV. A tutela das pessoas portadoras de deficiência pelo Ministério Público. Advocacia Pública \& Sociedade: direitos da pessoa portadora de deficiência. São Paulo, n. 1, p. 13-38, jan.1997.

7. BRANDÃO NRA. Gonartrose. Site Medicina Net. Disponível em: <http://www.medicinanet.com.br/conteudos/casos/5439/gonartrose.htm>. Acesso em: 24 jun 2018.

8. HARRES SS. Acupuntura no tratamento da gonartrose: Estudo randomizado, controlado e duplo-cego. Porto Alegre, 2008..

9. HINTERHOLZ EL, MUHLEN CA. Osteoartrose. Revista Brasileira de Medicina 2003; 60 (12): 87-91

10. MINISTÉRIO DO PLANEJAMENTO, ORÇAMENTO E GESTÃO. Manual de Perícia Oficial em Saúde do Servidor Público Federal. Brasília, 2014.

11. MUHLEN CA. Osteoartrose: como diagnosticar e tratar. Revista Brasileira de Medicina [serial on line] 2000. Disponível em: <http://www.moreirajr.com.br/revistas.asp?id materia=354\&fase=imprime>. Acesso em 30 jun 2018.

12. SILVA, SVG. Gonartrose: Osteoartrose de Joelho Capítulo 1. Disponível em: < http://sotstenio.blogspot.com.br/2009/05/gonartrose-osteoartrose-de-joelho.html>. Acesso em: 10 fev. 2018.

13. TJ-BA - APL: 01603381820098050001 , Relatora: Gardenia Pereira Duarte, Quarta Câmara Cível, Data de Publicação: $09 / 11 / 2016$. 